\title{
Knowledge, Attitude and Practices About Hiv/Aids Among Fsws (Female Sex Workers): A Case Study of Karachi
}

\author{
Kaneez Fatima Mamdani* \\ Munazza Madani** \\ Naila Usman Siddiqui***
}

\begin{abstract}
The present research was conducted on female sex workers (FSWs) to study the knowledge Attitude and Practices towards HIV/AIDS. Females are more vulnerable to HIV/AIDS as compared to males in Pakistan. The FSWs are on high risk due to the high-risk practices in their profession. Female sex workers are the major drivers of HIV/AIDS into general population. This is the group, which is ignored due to the social taboo, and stigma attached to their profession that in turn gave boom to these females and now they have become dangerous segment of the society. Present study was conducted on Napier Road, Karachi which is the oldest brothel area of Pakistan established during the rule of British. The data was collected from 180 FSWs through questionnaires. The findings showed that these females didn't use preventive measures against HIV/AIDS. Stigma, fear, threat and cultural constraint were some of the factors which have made them more vulnerable to HIV/AIDS. It was concluded that females in brothels were vulnerable to HIV/AIDS mainly due to their lifestyle, ignorance, use of drugs and little power to negotiate about the use of condoms, the safest form of prevention of STD's and HIV/AIDS. HIV prevalence is low in Pakistan even in this high risk group. It is suggested that the government should immediately launch security, educational and health services programs specifically for commercial sex workers in order to minimise the risks before it expounds and becomes epidemic.
\end{abstract}

Keywords: Female Sex Workers, HIV/AIDS, Cultural Constraints, lifestyle, ignorance,

* Assistant Professor, Department of Sociology, University of Karachi

** Assistant Professor, Department of Sociology, University of Karachi

*** Associate Professor, Department of Sociology, University of Karachi 


\section{Introduction}

The epidemic diseases have not only killed people; they have imposed a heavy burden on_families, communities and economies. The misery and devastation already caused by HIV/AIDS is enormous, HIV/AIDS is the death list epidemic of our time. Human immune deficiency virus (HIV) infection affects the immune system resulting in its weakness called immune deficiency. HIV is the beginning stage of the infection. The person remain symptom less and HIV anti bodies can be detected only by a blood test. The infection gradually progress to AIDS. The acquired immune deficiency syndrome, known as AIDS, is a disease of society in the most profound sense because of its link to specific ways of life. AIDS is a particularly deadly disease that destroys a person's immunity against infection, there by leaving the individual defenceless against a variety of afflictions like cancer, pneumonia, and a host of viruses ${ }^{1}$.

From the moment scientist identified HIV/AIDS, social responses of fear, denial, stigma and discrimination have accompanied the epidemic. HIV/AIDS is considered as a stigma and stigma is a power full tool. Stigma can be used to marginalize, exclude and exercise power over individuals who show certain characteristics while the societal rejection of certain social groups. For example: homosexuals, injecting drugs users and sex workers also may predate HIV/AIDS, the disease has, in many cases, reinforced this stigma. By blaming certain individuals or groups, society can excuse itself from the responsibility of caring for and looking after such populations. This is seen not in the manner in which 'outsider' groups are often blamed for bringing HIV into a country, but also in how such groups are denied access to the services and treatment they need. ${ }^{1}$

HIV/AIDS epidemic is rapidly spreading across boundaries of the world. Since 1987, Pakistan has also been included in the countries affected by AIDS pandemic. 38.1 million people have become infected with HIV since 2000 and around 25.3 million people have died due to AIDS-related illnesses. People living with HIV/AIDS were 36.9 million in Dec' 2014, this number has remained the same in 2015. In 2015, out of total infected people 15.8 million

1 Cockerham, W.C. 2009. Medical Sociology, $11^{\text {th }}$ Edition London: Prentice-Hall limited: $38-47$ 
were receiving antiretroviral therapy ${ }^{2}$. Millennium development goal for reducing HIV was achieved before the 2015 deadline. WHO, on the world's AIDS day on Dec' 1, 2015 gave new MGD target of zero HIV infected persons by the end of $2030^{3}$. The global statistics shows that better situation than South-Asia here the number of infected persons are increasing including Pakistan.

In Pakistan, health statistics reveal a very dangerous and alarming situation regarding the increasing number of AIDS patients. The most common modes of transmission of HIV/AIDS are heterosexual transmission, contaminated blood or blood products, where as other modes include injecting drug users, bisexual / homosexual relation and mother to child transmission were found in the reported cases of Pakistan.

Pakistan is presumed to be amongst one of the low prevalence as compared to other South Asian countries that are HIV/AIDS high risk regions. Sexual transmission is one of the main causes found in the reported HIV cases in Pakistan. Female sex workers (FSWs) and their client pivotally contribute in the heterosexual transmission of HIV / AIDS.

The data available in Pakistan is unclear but the total number of reported cases in all regions of Pakistan stands at 78000 [49000 - 140000] cases by December 2013 which increased to 94000 [58000 - 180000] in 2014. Data analysis indicated that mostly infection occurs in ages between 15-49 years, with male outnumbering female by a ratio of 7:1. Estimated 4,000 people die by HIV infection annually in Pakistan ${ }^{4}$.

2 UNAIDS. 2015. Worlds AIDS day report; Global Fact Sheet 2015, United Nations. Available at http://www.unaids.org/en/resources/campaigns/HowAIDSchanged everything/ factsheet. Retrieved in 2015

3 World Health Organization (WHO). 2016, World Health Statistics: 2015, Italy, WHO Press. 74-87

4 UNAIDS. 2015. Worlds AIDS day report; Global Fact Sheet 2015, United Nations. Available at http://www.unaids.org/en/resources/campaigns/HowAIDSchanged everything/ factsheet. Retrieved in 2015. 
Jhss, Vol. 7, No. 1, January to June, 2016

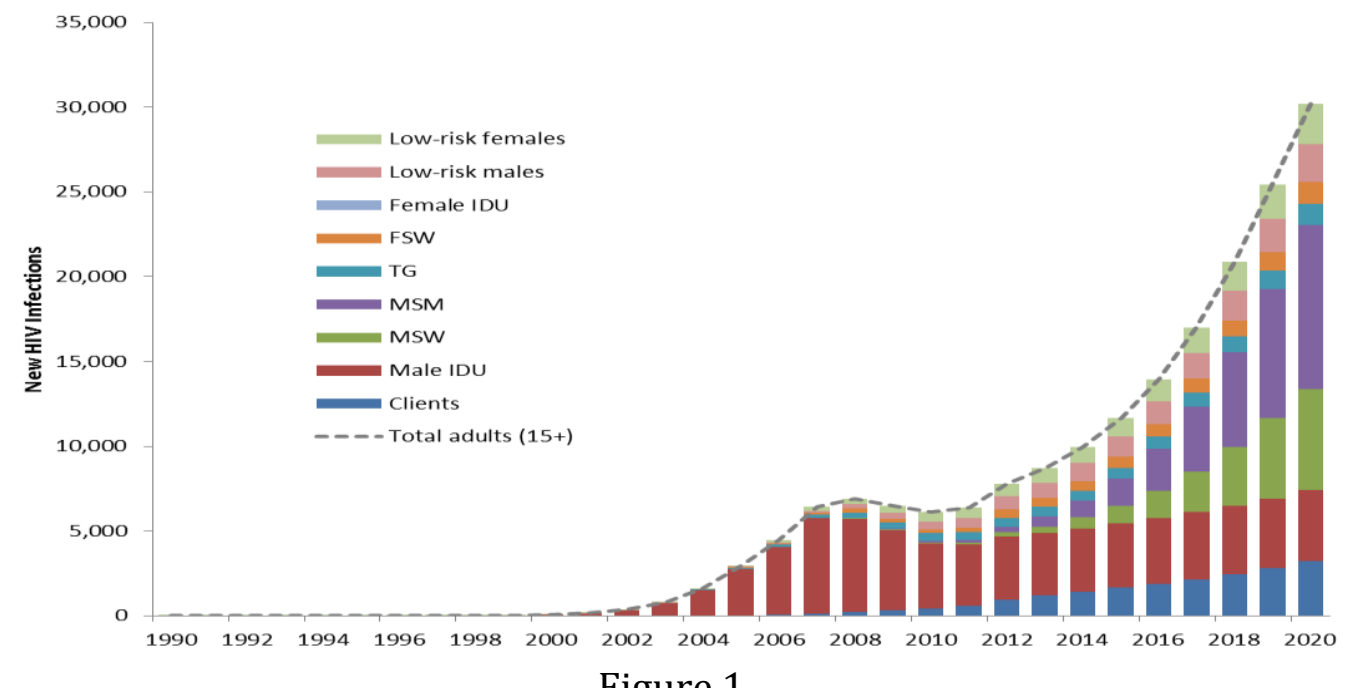

Figure 1

HIV New Infection - Spectrum / EPP 2014

Source: Pakistan Global AIDS Response Progress Report (GARPR) $2015^{5}$

Figure 1 shows the increasing trend of newly infected HIV/AIDS infected people in Pakistan from 1990 to 2014. It also indicates the estimated increase in the number till 2020 by high risk groups in Pakistan. The transmission trend closely stimulates with other developing countries of all the reported HIV/AIDS cases i.e. heterosexual route is the predominant mode of transmission (62\%). Other modes include infection through injecting drug abuse $(27.2 \%)$ contaminated blood and blood products (7\%); homo or bisexual sex (5\%); mother to child transmission $(2 \%)^{6}$.

\section{FSWs in Pakistan}

In many countries, FSWs were ignored until the advent of AIDS, when it became clear the sex workers were the highly vulnerable groups to STDs/STIs and HIV/AIDS infection due to their high risk profession and could quickly spread the virus to the large number of people. It is very important to vulnerable groups are specially sex workers to take initiatives

5 National AIDS Control Program. 2015. Pakistan Global AIDS Response Progress Report (GARPR) 2015: Country Progress Report, Islamabad, Ministry of Health, Pakistan

6 National AIDS Control Program. 2006. HIV Second Generation Surveillance In Pakistan: National Report Round II 2006-07, Canada Pakistan HIV/AIDS Surveillance Project, Ministry Of Health, Pakistan: 17-40. 
for appropriate preventive measures ${ }^{7}$. It is equally important to educate and built self confidence amongst the infected person so as to safeguard their social rights.

The estimated population of FSWs is $149,000-184,000$, the majority of which are located in major cities. HIV prevalence in Pakistan was 0.6 per cent in 2011, whereas it was $0.2 \%$ in 2007 showing increasing trend. Their average age in 2011 was 26.9 years. For $43.1 \%$ their mode of selling sex was through a Brothel, Kotikhana or Home-based mostly operating through a Madam, while $22.3 \%$ were street-based and $24.7 \%$ used cell phones for accessing clients. FSW reported an average of three clients a day. Condom use with clients was generally low as only $33.2 \%$ were using them. Out of the estimated FSWs in Pakistan, more than 70,000 FSWs were estimated for Karachi ${ }^{8}$. These FSWs enter into sex-work due to the increasing rates of poverty and economic opportunities, gender inequality, women trafficking, sexual exploitation and other domestic reasons. The GARPR (2015) ${ }^{9}$ report showed that only $5.2 \%$ of FSWs were benefitting from HIV prevention program where only $33.2 \%$ used condoms.

\section{Factors Increasing Sex Workers Vulnerability to HIV Infection}

Female sex workers are among the highest risk population groups exposed to HIV / AIDS to other STIs. The community of FSWs is highly vulnerable to STDs/ HIV/AIDS due to their high risk profession that increases their chances of infection with HIV. Lack of education, ignorance and economic needs remain to be the root causes of the problem.

Factors that appear to intensify sex workers vulnerability to and risk of HIV infection are:

\section{Stigmatization and Marginalization:}

Stigmatization and marginalization are often linked to sex workers, though indirectly through their clients or third parties involvement in sex work

7 Naqvi, S B and Uzma, Q. 2005. A Literature Review on Female Sex Workers in Pakistan, Islamabad, Population Association of Pakistan: 124-141.

8 National AIDS Control Program. 2015. Pakistan Global AIDS Response Progress Report (GARPR) 2015: Country Progress Report, Islamabad, Ministry of Health, Pakistan: 06-25.

9 National AIDS Control Program. 2015. Pakistan Global AIDS Response Progress Report (GARPR) 2015: Country Progress Report, Islamabad, Ministry of Health, Pakistan: 0625. 
(such as sex worker partners, police etc.). Double standards are found in almost all societies are succinctly characterized by an African sex worker: "It is only women who are downgraded from sleeping around not men. Men will always retain their dignity, but women will lose their dignity". Social norms often acknowledge only a limited range of acceptable roles for females, daughters, wives, mothers and homemakers ${ }^{10}$.

\section{Lack of Protective Legislation and Policies:}

Sex workers and their clients are not protected by the state laws and policies as an Islamic state; this segment of the society is not considered worthy of protection. If some form of laws are their but are not enforced properly. If a FSW is raped by anyone it is nearly impossible for them to bring charges against them. The poor socio-economic condition and lack of social control gives encouragement to third parties to behave in an unscrupulous manner. The situation created by this factor makes both sex workers and their clients susceptible to HIV infection.

\section{Limited Access to the Means of Information and Prevention:}

Sex workers especially FSWs' options for seeking health care, social and legal services are very minute. If they or their families have HIV and STIs or need protection from these diseases or any other related matter they are faced with many hurdles to get the assistance they require to solve their issues. In some private clinics such services are available to them but due to inconvenient hours \& locations, unwelcoming or judgmental attitudes on the part of the staff, make it difficult for them to take advantage of it. These facilities often charge high fees from them while overall poor quality of these facilities works as a deterrent for FSWs.

\section{Unsafe Sex Practices:}

FSWs and their clients are very much at risk of contracting HIV infection when there is lack of information regarding safe sex, skills of negotiation, and access to the preventive measures against this disease. Risk of contraction of the disease increases among both parties when there is increase in the frequency of unprotected intercourse. The stakeholders in this situation

10 Brown, L 2000. Sex Slaves in Asia: The Trafficking of Women In Asia, London, Collins Publisher: 145-151 
neither have the knowledge to protect themselves nor do they know how to do so. FSWs also lack the means (e.g. condoms, lubricants, safe sex skills) of protecting themselves. Personal negotiating power of sex workers especially female sex workers is deficient. Madams, pimps or managers of the sex workers strongly discourage the practices of safe sex and risk of HIV infection is compounded with the fear or threats of retaliation if they try to practice it ${ }^{11}$.

\section{Exposures To Risk Associated With Life Style:}

Life style of FSWs and their clients is very questionable putting them directly and indirectly on risk of infection. Substance abuse including alcohol consumption, use of enhancing drugs as Viagra is very common in this line of work. When they are under influence of these substances they tend to ignore safe sex. Sometimes these influences are associated with the increased STIs, which are attributed towards incorrect and flawed use of condoms. An injecting drug user can also transmit HIV to its partner they may be sex workers or their clients. Sexual violence is another factor associated with their life styles. The studies have shown violence against sex workers by their agents, clients, pimps and police. The major factor in spreading HIV around the world is the increased mobility of people due to international trades, businesses, jobs and vacations.

Migration of people due to social, economic and political disruptions often entails increase in the number of FSWs. This type of migration is genderspecific, creating more demand for sex in turn increased number of foreign prostitutes. Mostly migrated prostitutes are coming from the countries which have high STIs or HIV prevalence than the countries of destination. These migrants have illegal status which worsens the isolation and gives the opportunity to sex managers to exploit them creating dependency among FSWs. It therefore, limits their independence and prospect of practicing safe sex and accessing health care services ${ }^{12}$.

11 Brown, L. 2005. The Dancing girls Of Lahore: Selling Loves and Dreams in Pakistan, New York, Harper Collins Publisher: 43-52

12 Pakistan National AIDS Control Program. 2005. A Behavioural Mapping Study: Female Commercial Sex Workers in Lahore, Karachi and Multan, Karachi, Ministry of Health: 2225 


\section{Literature Review}

Khawaja \& et al (1997) ${ }^{13}$ reviewed both formally and informally published data available in Pakistan regarding prevalence of HIV/AIDS and its risk factors. Pakistan has low prevalence rates as compared to many other countries. The literature highlighted that though Pakistan is an Islamic society it does not mean that they will be protected against HIV. Pakistan had recognized the threats at that time and had started implementation of preventive and educational programmes but was lagging. Pakistan had been working with WHO for the fight against HIV although the commercial sex industry was neglected which is the highest risk population. Their study concluded that as the prevalence is low, Pakistan can easily reduce the threat of HIV by targeting the high risk groups as sex workers. Evans \& Lambert $(1997)^{14}$ paper discussed health-seeking among a group of female sex workers in Calcutta, India. The findings indicated that the cultural biases and constraints are the major factors in seeking health services. Vanwesenbeeck $(2001)^{15}$ reviewed international researches from psychology and sociology on prostitution from 1990-2000. The findings from all those researches confirmed that many aspects of stigmatization still exist in different societies. The literature also showed that sex workers were least concerned about safe sex against HIV. Bokhari \& et al (2007) ${ }^{16}$ studied HIV prevalence among FSWs, MSWs, transgender and IDUs in Karachi and Lahore. It was found that unprotected commercial sex activity had become high in both men and women. 4\% of MSWs were tested positive for HIV whereas it was low for FSWs. Mayhew \& et al (2008) ${ }^{17}$ investigated the association between social

13 Khawaja, Z A \& et al. 1997. HIV/AIDS and its risk factors in Pakistan: Editorial Review AIDS: Official Journal of International AIDS society, Vol. 11 (7), 843-848 available at URL http://journals.lww.com/aidsonline/Fulltext/1997/07000/HIV_AIDS_and_its_risk_facto r_in_Pakistan .2 aspx retrieved in 2016.

14 Evans, C \& Lambert, H. 1997. Health-seeking strategies and sexual health among female sex workers in urban India: Implications for research and service provision, Journal of Social Science \& Medicine, Science Direct. Volume 44 (12), 1791-1803

15 Vanwesenbeeck, I. 2001. Another Decade of Social Scientific Work on Sex Work: A Review of Research 1990-2000, Annual Review of Sex Research, Online Journal of Taylor \& Francis Group. 2012 Vol.12(1):242-289 available at URL http://www.tandfonline.com /doi/abs/10.1080/ 10532528. 2001.10559799 Retrieved in 2016.

16 Bokhari, A. 2007. HIV risk in Karachi, Lahore, Pakistan: An Emerging Epidemic in injecting and Commercial Sex Networks, International Journal of STDs and AIDS, Sage Publications, vol. 18 (7), 486-492.

17 Mayhew, S \& et al. 2008. Protecting the unprotected: mixed-method research on drug use, sex work and rights in Pakistan's fight against HIV/AIDS, International Journal of 
and sexual linkages in human rights abuses among injecting drug users and male \& female sex workers. The results showed that human rights abuses were very frequent among these groups increasing their risks against HIV. The study also indicated that discrimination was at high levels where clients, police and managers harass and exploit them. The study suggested that both legal and health programs to be initiated immediately to minimise not only discrimination but also reducing the potential for the spread of HIV before it becomes epidemic. Scambler \& Paoli (2008) ${ }^{18}$ study revealed that shame and blame and attached labeling process related to FSWs were very much the part of the structure nexus of these cities (London, Bangkok and Kolkarta). Hawkes S \& et al (2009) ${ }^{19}$ paper studied the extent of spread of HIV among commercial sex workers in Rawalpindi and Abbottabad, Pakistan. HIV prevalence as low among sex workers although STIs level were high. Awareness and knowledge about HIV was lacking. Their findings were consistent with other studies suggesting programs for intervention before HIV becomes epidemic. The programs should not only be comprised of awareness campaigns but also upholding the recognition and protection of human rights. Catherine \& et al (2010) ${ }^{20}$ assessed the prevalence of HIV, syphilis, and hepatitis $B$ and $C$ virus and their related risk behaviors among FSWs in three cities of Afghanistan. The paper concluded that though prevalence of HIV, HCV, and syphilis was currently low; unsafe, unprotected and risky sexual practices were widespread and frequent showing urgent introduction of programs for the prevention of these diseases.

Sexually Transmitted Infections Vol.85(2) available at URL. http://sti.bmj.com/ content/85/Suppl 2 /ii31 Retrieved in 2016.

18 Scambler, G \& Paoli, F. 2008. Health work, female sex workers and HIV/AIDS: Global and local dimensions of stigma and deviance as barriers to effective interventions, Journal of Social Science \& Medicine. Science Direct. Volume 66 (8): 1848-1862.

19 Hawkes S \& et al. 2009. HIV and other sexually transmitted infections among men, transgender and women selling sex in two cities in Pakistan: a cross-sectional prevalence survey, International Journal of Sexually Transmitted Infections Volume 85 (2) available at URL. http://sti.bmj.com/content/ 85/Suppl_2/ii8 Retrieved in 2016.

20 Catherine S. T \& et al. 2010. HIV, hepatitis B, and hepatitis C prevalence and associated risk behaviours among female sex workers in three Afghan cities AIDS. 2010 Jul; Vol. 24(02): S69-S75 available at URL. http://www.ncbi.nlm.nih.gov/pmc/ articles/PMC3650731/\# Retrieved in 2016. 
Jhss, Vol. 7, No. 1 , January to June, 2016

\section{Justification of the Study}

Prostitution (sex work) is one of the oldest sociological problems that have come into existence with the rise of civilization. Even though it is illegal in Pakistan but its existence is a known fact. It is not only a social but also a medical problem, in nearly all settings female sex workers are the stigmatized group of population. Their very existence challenges the standard of families and reproduction-oriented sexual morality found in most societies, yet they exist nearly everywhere. With the advent of HIV pandemic they have been the first group in many nations to be targeted as vectors and seen as a danger to the general population. As modern society is working towards the more human approach towards female sex workers based on a deeper understanding of the situation, this work would serve the need of the many specialist engaged in the endeavour. Sociologist psychologist, medical personnel, social workers and the people who are interested to do research on this segment of the society will benefit from this research.

In fact this is a bold attempt in as much as that it is the first of its kind of scientific sociological research on the female sex workers in contemporary Karachi in Napier Road. Researchers have accepted the challenge as they were interested to uncover the basis of social taboo, and target the group at high risk of HIV/AIDS. In order to combat with this disease exploring the knowledge, attitude and practices of HIV/AIDS among female sex workers is the proper way.

\section{Focus of the Study}

In the present research, researchers focused on the knowledge of female sex workers about HIV/AIDS, their attitude towards the disease and to find out the practices of female sex worker for the prevention of the disease as these are the females who are at the higher risk to HIV/AIDS. Negative attitude, beliefs and values or misinformation about HIV/AIDS increases their susceptibility to the disease. Research also focuses on the causes of entry in the profession, ethnic background, their cultural setup and their general health condition as these are the factors which play pivotal role on the perception of the disease. 


\section{Objectives}

- To study the gap between knowledge and practices of preventive measures of HIV / AIDS among female sex workers.

- To explore the knowledge and prevalence of HIV/AIDS.

- To analyse the nature and types of sexual behaviour.

\section{Research Methodology}

The research approach used in the study was quantitative research ${ }^{21}$. The data was collected by questionnaires. 180 questionnaires were filled from the target population. For the presentation of the data researchers have used the frequency and percentage distribution tables and graphs. It was found that most of the respondents were illiterate therefore interview schedule (a questionnaire to be filled by the researchers/data collectors) was used for data collection. SPSS was used to present and examine the data. Chi-square and p-value were used to interpret and analyse the data.

\section{Major Findings:}

Table 1 \& Chart 1

Frequency \& Percentage Distribution of Respondents by their Age Groups

\begin{tabular}{cccc}
\hline S. & Age & Frequency & Percentage\% \\
No & Group & Frequ & 21 \\
\hline a & $12-19$ & 38 & 37.80 \\
b & $20-27$ & 68 & 32.20 \\
c & $28-35$ & 58 & 6.70 \\
d & $36-43$ & 12 & 2.20 \\
e & $44-51$ & 4 & $\mathbf{1 0 0}$ \\
\hline & Total & $\mathbf{1 8 0}$ & \\
\hline
\end{tabular}

21 Babbie, E. P. 2005. Practice Social Research, California, Wadsworth Publishing Co. Inc Belmol: 146-158. 
Jhss, Vol. 7, No. 1 , January to June, 2016

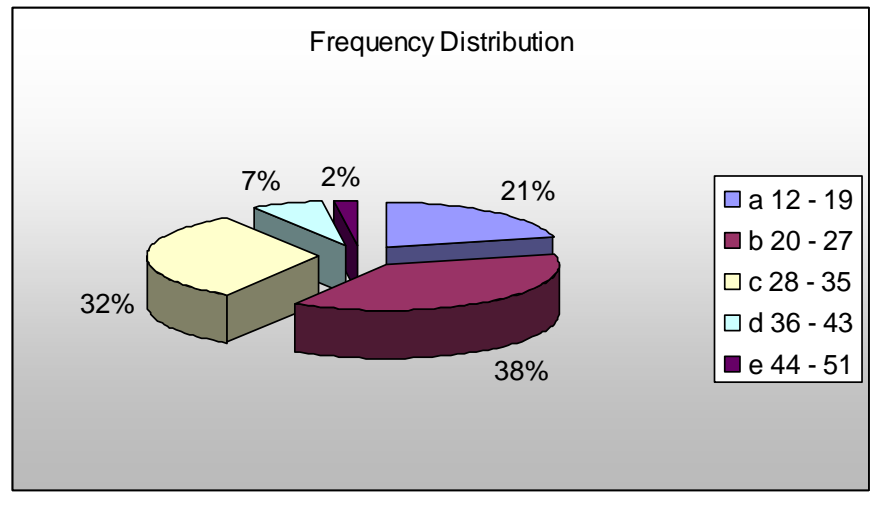

Table 1 shows that out of 180 respondents, $21 \%$ of respondents were in age group (12-19 years), $37.80 \%$ of the respondent were in age group (20-27), $32.20 \%$ of the respondent were in age group (28-38), $6.70 \%$ of the respondent were in age group (36-43), 2.20\% of the respondent were in age group (44-51) years. The statistics support the fact that FSWs median age is between 20-27 years.

Table 2 \& Chart 2

Frequency \& Percentage Distribution of Respondents by their Educational Status

\begin{tabular}{|c|c|c|c|}
\hline $\begin{array}{l}\text { S. } \\
\text { No }\end{array}$ & $\begin{array}{c}\text { Educational } \\
\text { Status }\end{array}$ & $\begin{array}{c}\text { Frequency } \\
\text { Distribution }\end{array}$ & $\begin{array}{c}\text { Percentage } \\
\%\end{array}$ \\
\hline $\mathrm{a}$ & Illiterate & 116 & 64.44 \\
\hline $\mathrm{b}$ & Primary & 54 & 30.00 \\
\hline c & Middle & 6 & 3.33 \\
\hline \multirow[t]{2}{*}{ d } & Matric & 4 & 2.22 \\
\hline & Total & 180 & 99.99\% \\
\hline
\end{tabular}

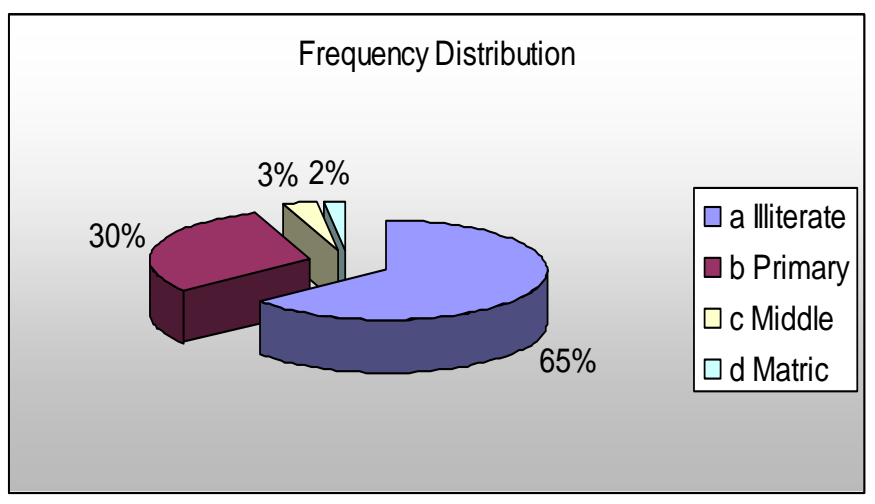


Out of 180 respondents $64 \%$ were illiterate, $30 \%$ had primary education, $3.3 \%$ had middle, and only $2.2 \%$ were matriculate.

Table 3 \& Chart 3

Frequency \& Percentage Distribution of Respondents According To Their Use of Condoms

\begin{tabular}{cccc}
\hline S. No & Use Of Condom & $\begin{array}{c}\text { Frequency } \\
\text { Distribution }\end{array}$ & Percentage\% \\
\hline a & Always & 86 & 47.77 \\
b & Sometimes & 82 & 45.55 \\
c & Never & 10 & 5.56 \\
d & No-response & 2 & 1.11 \\
\hline & Total & $\mathbf{1 8 0}$ & $\mathbf{9 9 . 9 9}$ \\
\hline
\end{tabular}

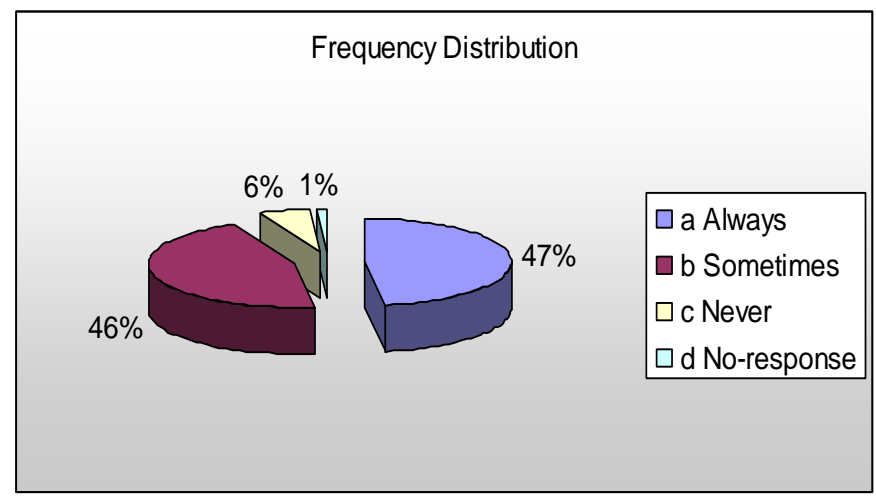

Table 3 indicates that $47.77 \%$ have always used condoms, $45.55 \%$ sometimes used the condoms whereas 5.5\% have never used them.

Table 4 \& Chart 4

Frequency \& Percentage Distribution of Respondents According To the Practice of Anal Sex

\begin{tabular}{cccc}
\hline S.No & $\begin{array}{c}\text { Practice } \\
\text { of Anal Sex }\end{array}$ & $\begin{array}{c}\text { Frequency } \\
\text { Distribution }\end{array}$ & $\begin{array}{c}\text { Percentage } \\
\mathbf{\%}\end{array}$ \\
\hline a & Yes & 90 & 50 \\
b & No & 14 & 7.77 \\
c & No-response & 76 & 42.22 \\
\hline & Total & $\mathbf{1 8 0}$ & $\mathbf{9 9 . 9 9}$ \\
\hline
\end{tabular}




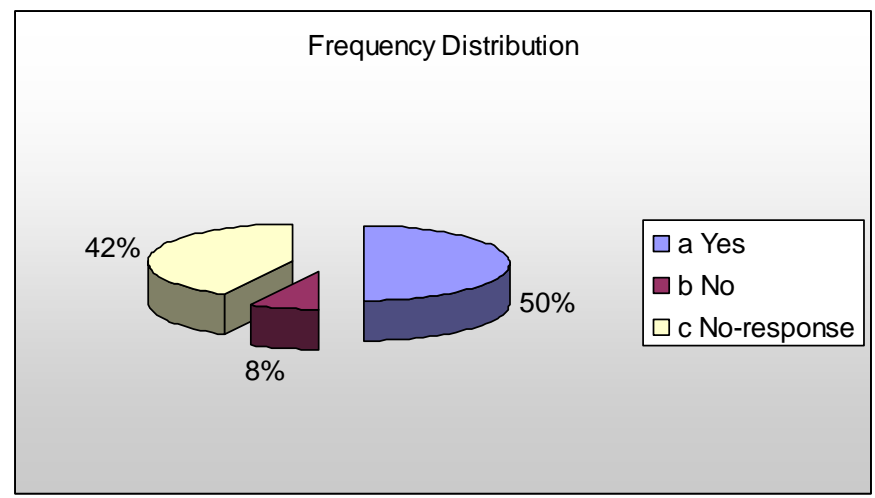

Table 4 highlights that $50 \%$ of FSWs were practicing anal sex, $7.77 \%$ were not practicing anal sex and $42.22 \%$ gave no response indicating that they were either ashamed or shy about having this practice. They might not simply be telling the truth so they had remained silent about it.

Table 5 \& Chart 5

Frequency \& Percentage Distribution of Respondents According To Their Practice of Oral Sex

\begin{tabular}{cccc}
\hline S.No & $\begin{array}{c}\text { Practice } \\
\text { of Oral Sex }\end{array}$ & $\begin{array}{c}\text { Frequency } \\
\text { Distribution }\end{array}$ & Percentage\% \\
\hline a & Yes & 40 & 22.22 \\
b & No & 72 & 40.00 \\
c & No-response & 68 & 37.77 \\
\hline & Total & $\mathbf{1 8 0}$ & $\mathbf{9 9 . 9 9}$ \\
\hline
\end{tabular}

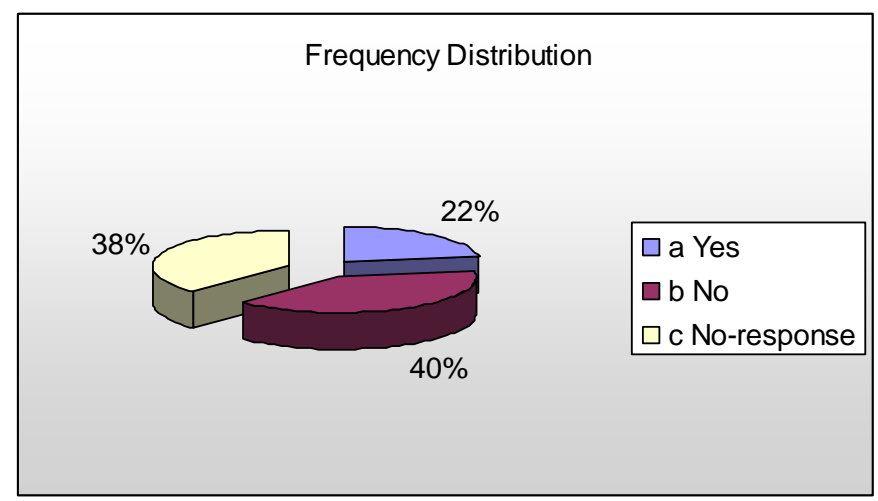


The above table indicates that approximately $22 \%$ of FSWs were practicing oral sex, $40 \%$ were not practicing oral sex while $37.8 \%$ gave no response indicating they were not willing to talk freely regarding this matter which they thought was very personal.

Table 6 \& Chart 6

Frequency \& Percentage Distribution of Respondents According To the Knowledge of the Term HIV/AIDS

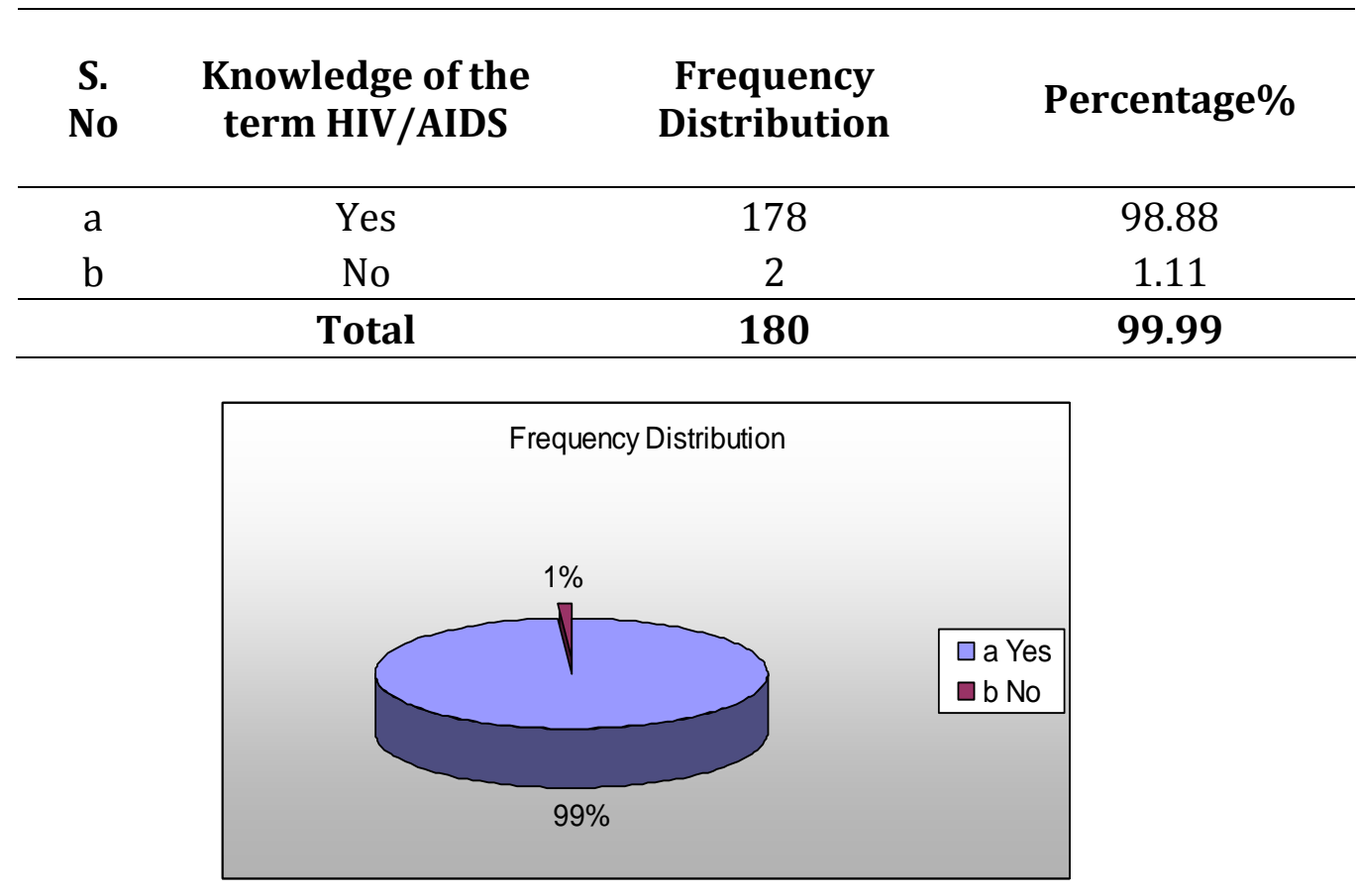

99\% of FSWs were aware of the term HIV/AIDS, while1.11\% hadn't heard about HIV/AIDS. Although knowing or hearing about the term doesn't mean that they knew about the serious implications behind this disease. 
Table 7 \& Chart 7

Frequency \& Percentage Distribution of Respondents According To the Awareness about HIV/AIDS

\begin{tabular}{cccc}
\hline S. No & $\begin{array}{c}\text { Awareness About } \\
\text { HIV/AIDS }\end{array}$ & $\begin{array}{c}\text { Frequency } \\
\text { Distribution }\end{array}$ & Percentage\% \\
\hline a & Complete Information & 88 & 48.88 \\
b & Partial Information & 10 & 5.55 \\
c & Very little info. & 76 & 42.22 \\
d & Don't know & 6 & 3.33 \\
\hline & Total & $\mathbf{1 8 0}$ & $\mathbf{9 9 . 9 8}$ \\
\hline
\end{tabular}

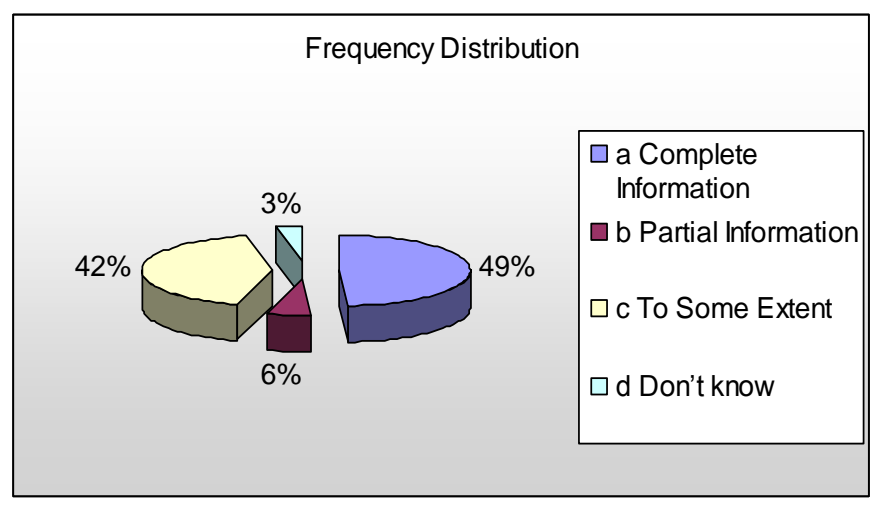

Table 7 highlights that around $49 \%$ had complete information about HIV/AIDS, 5.55\% had partial information about HIV/AIDS whereas $42.22 \%$ had very little information and $3.33 \%$ had no knowledge at all about the disease.

Table 8 \& Chart 8

Frequency \& Percentage Distribution of Respondents according To Their Knowledge of safety Measures against HIV/AIDS

\begin{tabular}{cccc} 
S.No & $\begin{array}{c}\text { Knowledge of Safety } \\
\text { Measures For HIV/AIDS }\end{array}$ & $\begin{array}{c}\text { Frequency } \\
\text { Distribution }\end{array}$ & $\begin{array}{c}\text { Percentage } \\
\mathbf{\%}\end{array}$ \\
\hline a & Complete Information & 122 & 67.77 \\
b & Partial Information & 20 & 11.11 \\
c & Very little info. & 32 & 17.77 \\
d & Don't know & 6 & 3.33 \\
\hline & Total & $\mathbf{1 8 0}$ & $\mathbf{9 9 . 9 8}$ \\
\hline
\end{tabular}

62 


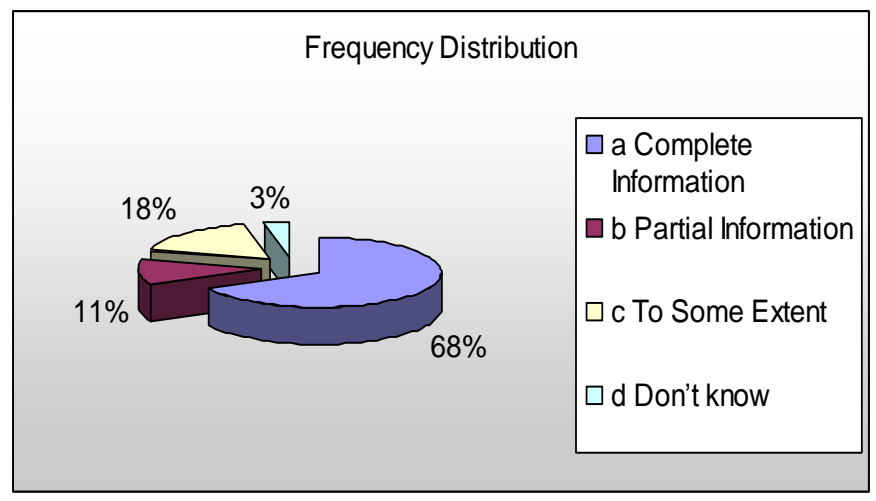

Approximately $68 \%$ of FSWs had complete information about safety measures against HIV/AIDS, $11.11 \%$ had partial information about safety measures while $17.8 \%$ had very little information and $3.33 \%$ had no knowledge.

Table 9 \& Chart 9

Frequency \& Percentage Distribution of Respondents According To the Use of Drugs during Sexual Intercourse in Last Six Month

S. Use of drugs During Sexual No Intercourse In Last Six Month

Frequency

Distribution
Percentage $\%$

\begin{tabular}{cccc}
\hline $\mathrm{a}$ & Yes & 130 & 72.22 \\
$\mathrm{~b}$ & No & 48 & 26.66 \\
$\mathrm{c}$ & No-response & 2 & 1.11 \\
\hline & Total & $\mathbf{1 8 0}$ & $\mathbf{9 9 . 9 9}$ \\
\hline
\end{tabular}

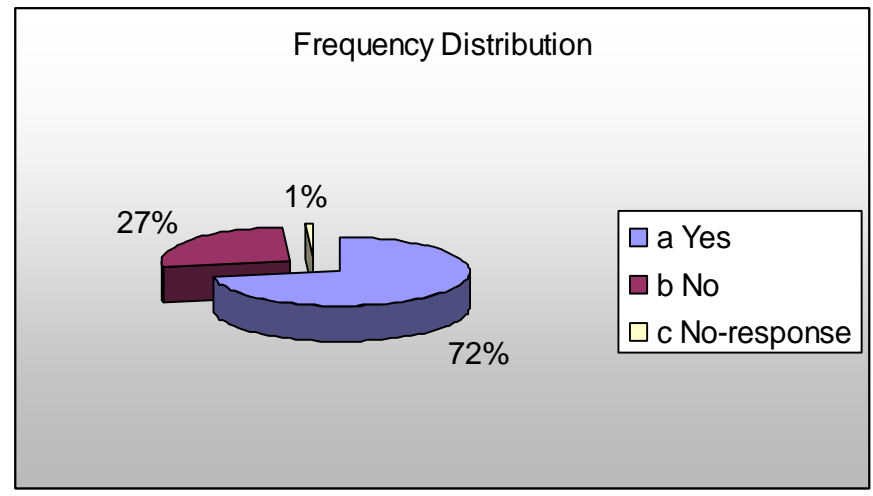


Table 9 points out that out of 180 respondents, $72 \%$ used drugs during sexual intercourse in last six month, $26.66 \%$ did not use drugs during sexual intercourse in the last six month, while $1.11 \%$ gave no response.

\section{Discussion}

Chart 10 presents the association between educational status and use of condoms. P-value $<0.004$ shows significant association between educational status and use of condoms. The data also supports the findings that the highest number of respondent who were using condoms had some degree of education whereas illiterate FSWs weren't also using condoms. They mostly were using condom as a contraceptive method and not as a safety measure. The literacy rate of the respondent was very low among the respondent, however the awareness about the usage and importance of condoms came from the NGOs working with this high risk group. The majority of the FSWs, who were using condoms, were getting them free of cost from those NGOs specifically AMAL Foundation.

\section{Chart 10}

\section{Relationship between Educational Status and Use of Condom}

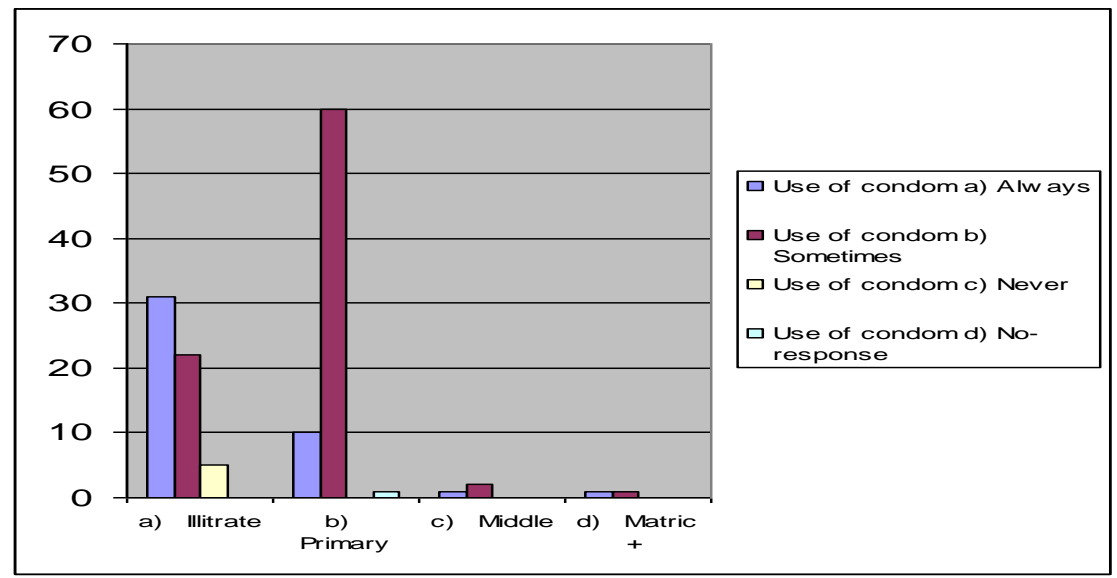

Chart 11 shows relationship between awareness about HIV/AIDS and knowledge of safety methods. P-value $<0.001$ of the data indicates strong relationship between awareness about HIV/AIDS and knowledge of safety methods. The large number of respondents had complete information of safety measures against HIV/AIDS, although the number of FSWs with partial and very little knowledge is relatively higher than the said population with awareness. Awareness of HIV/AIDS was found due to the presence of the 
NGOs working on HIV/AIDS prevention in FSWs. Respondent were using safety methods due to their particular profession although they were using both safe and unsafe methods showing lack of awareness of both HIV/AIDS and its safety methods.

\section{Chart 11}

\section{Relation between Awareness about HIV / AIDS and Knowledge of Safety Methods}

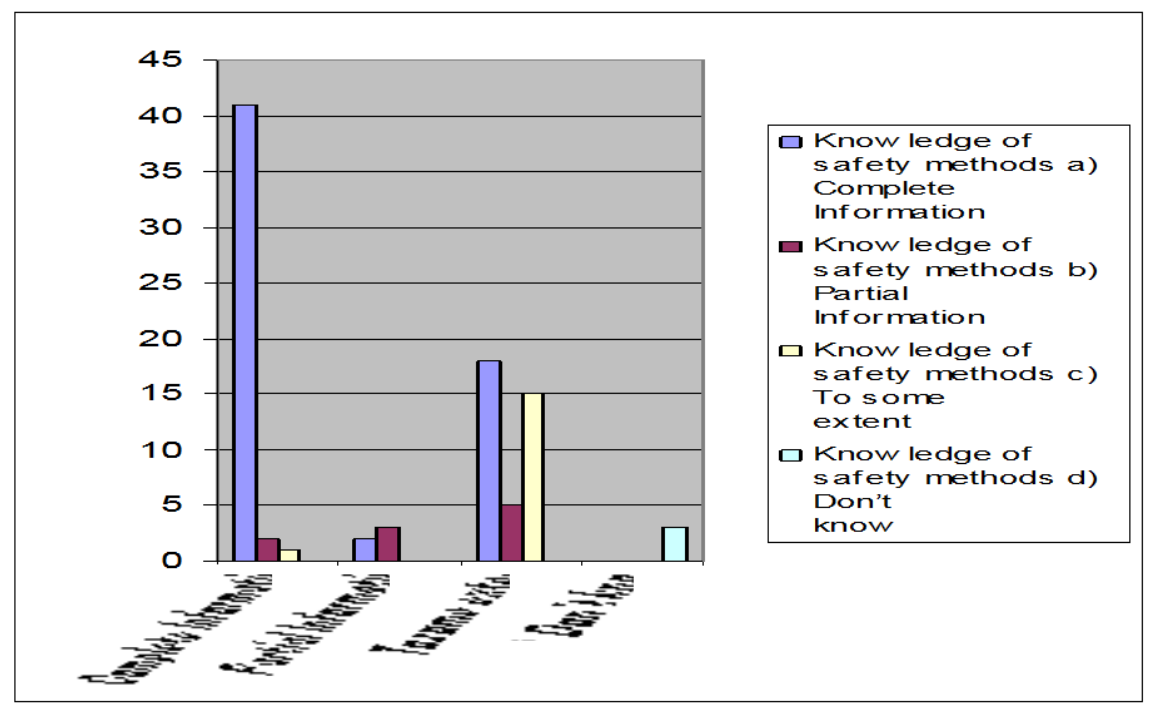

The relationship of cross tabulation is shown in chart 12 between use of condoms and knowledge about safety methods. P-value $<0.01$ shows significant association between use of condoms and knowledge about safety methods. In order to earn more money FSWs were involved in every type of sex. The FSWs who practiced both anal and oral sex had more clients. FSWs wanted to use condoms mainly for the contraceptive purposes and not only for safe sex but they didn't have the choice to use the condoms when their clients refused to do so otherwise they would not only lose their clients but their clients would go to other FSWs who were their competition. 


\section{Chart 12}

\section{Relation between Use of Condom and Knowledge about Safety Method}

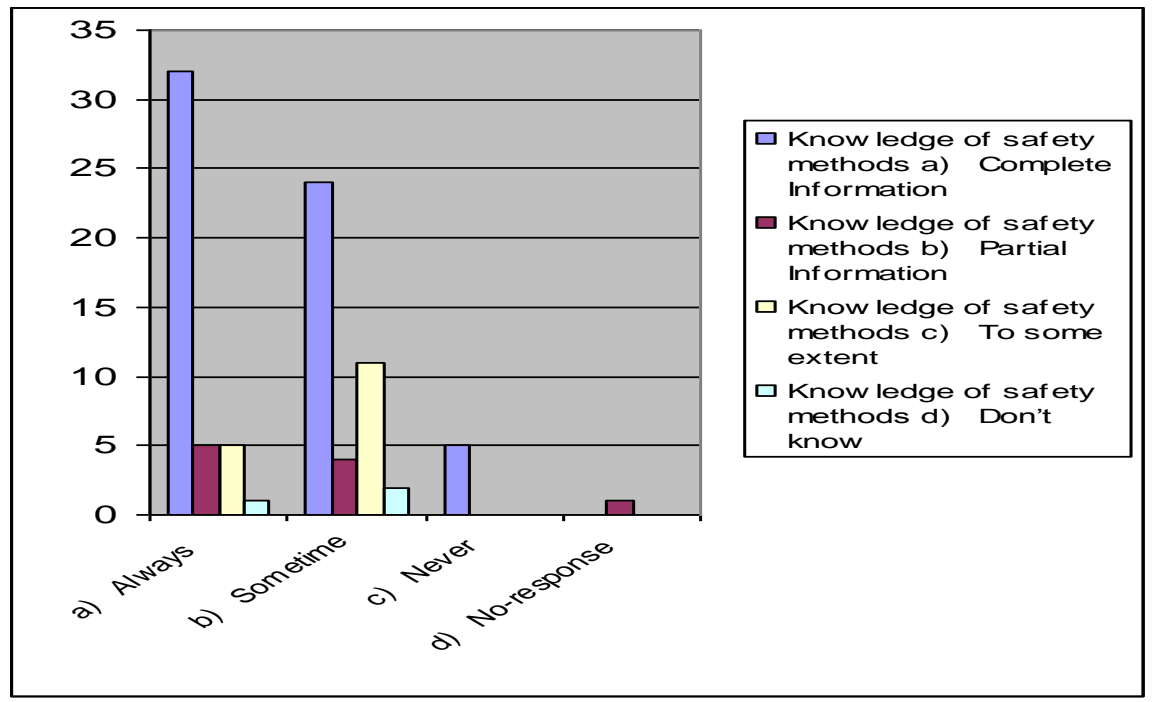

\section{Conclusion}

In almost every country, sex workers comprise a focal point of the epidemic, because women who provide sex for many men, infection can easily accumulate among them. Because a larger portion of the population buys or sell sex then engages in the other behaviours that carry an elevated risk of HIV infection. One third population of the world are effected to HIV/AIDS in between the range of $15-24$ years. First it was very familiar only European area like USA and Africa. Now it is spreading rapidly in Asia. HIV / AIDS is not only victimize the individual but it effect very rapidly to whole family, community country as well as in world. Unfortunately, this disease has no special drug treatment and it is a big dilemma that no hope for such curable drugs in near future. Female sex workers are the victims of discrimination often violently intense, trafficking, legal persecution and social ambivalence, as well as one of the first occupational groups to become heavily infected. From them, the infection passes back to their clients and into the general population of women, men and children.

According to $\mathrm{WHO}^{22}$, Pakistan has been considered as low prevalence of HIV/AIDS. Some independent investigator claims that prevalence of

22 World Health Organization (WHO). 2015. Global health sector response to HIV, 20002015: focus on innovations in Africa: progress report, France, WHO Press: 19-27 
HIV/AIDS in Sindh in female sex worker is only $0.7 \%$, but the situation of Pakistan is alarming, as it is estimated by World Bank, that the population of female sex worker only in Karachi is 62,000, and further researches suggest that it is more than that. The spread of female sex worker in society is like cancer. In our society, these female are considered as taboo and cannot discuss them openly. But it is the need of time to discuss these types of taboos.

The major misconception which is very common about this lethal disease (HIV/AIDS) is only to adopt unnatural contraceptive style or living but there is need to identify other sources of carries such as DTD, PDD, use of unhygienic utensils and syringes and blades. One of the clearest public health from the HIV epidemic is that protecting human rights of sex workers is one of the best ways to protect the rest of society from HIV.

\section{Recommendations:}

- The state should provide them with both security and education especially, there is a need to provide them with security against the police harassment as they misuse their authority and exploits them.

- There is also a need to educate these women and provide them with secondary occupation.

- Sex workers need regular access to high quality STI screening and treatment services that also reinforces other preventive services.

- Government should appoint trained LHW's in these areas for the purpose of regular check-ups.

- Female sex workers should be restricted to a particular area (muhalla) and they should not be forced to move out of those specified areas so that the quality of health services could be made accessible to them in timely manner.

- Strengthening the family and community structure to create a strong culture for protection of young people from sexual exploitation by making healthy public policy. 
Jhss, Vol. 7, No. 1, January to June, 2016

- There is a great need of involvement of the specialists such as sociologist psychologist, medical personnel and social workers to do not only research on this segment of the society but also participate in the active intervention so as to reduce the risk of sexually transmitted diseases especially HIV/AIDS. They could ensure the social, political and security environment support for the proper provision of appropriate HIV prevention services to female sex workers.

- Closing our eyes towards sex industry will not make it go away. Providing good prevention and care programs on large scale will make it safer. 


\section{References}

Babbie, E. P. 2005. Practice Social Research, California, Wadsworth Publishing Co. Inc Belmol: 146-158.

Bokhari, A. 2007. HIV risk in Karachi, Lahore, Pakistan: An Emerging Epidemic in injecting and Commercial Sex Networks, International Journal of STDs and AIDS, Sage Publications, vol. 18 (7), 486-492.

Brown, L 2000. Sex Slaves in Asia: The Trafficking of Women in Asia, London, Collins Publisher: 145-151

Brown, L. 2005. The Dancing girls Of Lahore: Selling Loves and Dreams in Pakistan, New York, Harper Collins Publisher: 43-52.

Catherine S. T \& et al. 2010. HIV, hepatitis B, and hepatitis C prevalence and associated risk behaviours among female sex workers in three Afghan cities AIDS. 2010 Jul; Vol. 24(02): S69-S75 available at URL. http://www.ncbi.nlm.nih.gov/pmc/articles/PMC3650731/\#

Retrieved in 2016.

Cockerham, W.C. 2009. Medical Sociology, 11th Edition London: Prentice-Hall limited: 38-47.

Evans, C \& Lambert, H. 1997. Health-seeking strategies and sexual health among female sex workers in urban India: Implications for research and service provision, Journal of Social Science \& Medicine, Science Direct. Volume 44 (12), 1791-1803.

Hawkes S \& et al. 2009. HIV and other sexually transmitted infections among men, transgender and women selling sex in two cities in Pakistan: a crosssectional prevalence survey, International Journal of Sexually Transmitted Infections Volume 85 (2) available at URL. http://sti.bmj.com/content/ 85/Suppl_2/ii8 Retrieved in 2016.

Khawaja, Z A \& et al. 1997. HIV/AIDS and its risk factors in Pakistan: Editorial Review AIDS: Official Journal of International AIDS society, Vol. 11 (7), 843848 available at URL http://journals.lww.com/ aidsonline/Fulltext $\not 1997 / 07000 /$ HIV AIDS and its risk factor in Pakistan.2.aspx Retrieved in 2016. 
Mayhew, S \& et al. 2008. Protecting the unprotected: mixed-method research on drug use, sex work and rights in Pakistan's fight against HIV/AIDS, International Journal of Sexually Transmitted Infections Vol.85(2) available at URL. http://sti.bmj.com/content/85/Suppl 2 /ii31.short Retrieved in $\underline{2016}$.

Naqvi, S B and Uzma, Q. 2005. A Literature Review on Female Sex Workers in Pakistan, Islamabad, Population Association of Pakistan: 124-141.

National AIDS Control Program. 2006. HIV Second Generation Surveillance In Pakistan: National Report Round II 2006-07, Canada Pakistan HIV/AIDS Surveillance Project, Ministry Of Health, Pakistan: 17-40.

National AIDS Control Program. 2015. Pakistan Global AIDS Response Progress Report (GARPR) 2015: Country Progress Report, Islamabad, Ministry of Health, Pakistan: 06-25.

Pakistan National AIDS Control Program. 2005. A Behavioural Mapping Study: Female Commercial Sex Workers in Lahore, Karachi and Multan, Karachi, Ministry of Health: 22-25.

Scambler, G \& Paoli, F. 2008. Health work, female sex workers and HIV/AIDS: Global and local dimensions of stigma and deviance as barriers to effective interventions, Journal of Social Science \& Medicine. Science Direct. Volume 66 (8): 1848-1862.

UNAIDS. 2015. Worlds AIDS day report; Global Fact Sheet 2015, United Nations. Available at http://www.unaids.org/en/resources/campaigns/ HowAIDSchanged everything/ factsheet. Retrieved in 2015.

Vanwesenbeeck, I. 2001. Another Decade of Social Scientific Work on Sex Work: A Review of Research 1990-2000, Annual Review of Sex Research, Online Journal of Taylor \& Francis Group. 2012 Vol.12 (1), 242-289 available at URL http://www.tandfonline.com/ doi/abs/10.1080/105325 28. $\underline{2001.10559799}$ Retrieved in 2016.

World Health Organization (WHO). 2015. Global health sector response to HIV, 2000-2015: focus on innovations in Africa: progress report, France, WHO Press: 19-27.

World Health Organization (WHO). 2016, World Health Statistics: 2015, Italy, WHO Press. 74-87. 